\title{
Critical Analysis of Brain Magnetic Resonance Images Tumor Detection and Classification Techniques
}

\author{
Zahid Ullah ${ }^{1}$, Prof. Su-Hyun Lee*2, Donghyeok $\mathrm{An}^{3}$ \\ Department of Computer Engineering \\ Changwon National, Changwon \\ South Korea
}

\begin{abstract}
The image segmentation, tumor detection and extraction of tumor area from brain MR images are the main concern but time-consuming and tedious task performed by clinical experts or radiologist, while the accuracy relies on their experiences only. So, to overcome these limitations, the usage of computer-aided design (CAD) technology has become very important. Magnetic resonance imaging (MRI) and Computed Tomography (CT) are the two major imaging modalities that are used for brain tumor detection. In this paper, we have carried out a critical review of different image processing techniques of brain MR images and critically evaluate these different image processing techniques in tumor detection from brain MR images to identify the gaps and limitations of those techniques. Therefore, to obtain precise and better results, the gaps can be filled and limitations of various techniques can be improved. We have observed that most of the researchers have employed these stages such as Pre-processing, Feature extraction, Feature reduction, and Classification of MR images to find benign and malignant images. We have made an effort in this area to open new dimensions for the readers to explore the concerned field of research.
\end{abstract}

Keywords-Magnetic Resonance Imaging (MRI); Computed Tomography (CT); MRI classification; tumor detection; digital image processing

\section{INTRODUCTION}

Due to abnormal cell development, the brain tumor begins and grows in an uncontrolled way. The brain cells of a human brain can specifically ruin by the tumor. Different brain tumors are illustrated in Fig. 1. The most dangerous form of tumors is malignant tumors. Every year fourteen thousand deaths caused due to malignant tumors. The tumor stages are divided into different grades due to severity levels such as grade 1 , grade 2, grade 3 , and grade 4 . The grade 1 level is the least dangerous tumor and this type of tumor grows slowly and gradually. For this type of tumor grade, treatment via surgery might be successful. Ganglioglioma, gangliocytoma, and pilocytic astrocytoma are the different cases of grade 1 brain tumor. In the second grade, grade 2 tumor also grows slowly [24], and this type of tumor looks irregular using the microscopic instrument. The third one is grade 3 tumor which is also malignant and there is no significant difference between grade 3 and grade 2 . The maximum malignant tumor is grade 4 and the example of grade 4 tumor is Glioblastoma Multiforme [25].
Different image processing techniques have been used for tumor detection. Segmentation of images is one of them. The image segmentation aim is to segment an image into equal parts and find the region of interest (ROI) [26-27].

Nowadays, various imaging modalities are available such as Magnetic Resonance Imaging (MRI), X-Ray, Positron Emission Tomography (PET), Ultrasound, and Computed Tomography (CT) scan. In the given imaging modalities, magnetic resonance imaging generates good quality images and these images are extremely helpful for clinical diagnosis and biomedical research. MRI is particularly useful in examining the soft tissues in the human body.

Computed Tomography (CT) scan and Magnetic Resonance Imaging (MRI) are the two most useful imaging modalities to examine brain life structure. However, Magnetic resonance imaging is currently a widely used method as it produced high-quality medical images among all the imaging modalities. MRI is a non-invasiveness technique and it discriminates the soft tissue [28]. Magnetic resonance imaging (MRI) gives accurate information on the internal human body. MRI demonstrates the physiological or pathological variations of human tissues. MRI is mostly utilized when treating prostate cancers, brain, foot, and ankle. MRI can be used for the identification of different diseases, such as Alzheimer's, Parkinson, Stroke and Brain tumors diseases. The performance of MRI is far better than a CT scan. The MRI works effectively for soft tissues in the body, such as the brain, while the CT scan is suitable for hard body tissues such as bones.

Furthermore, image segmentation is a necessary task which is nowadays carried out manually by most physicians as they obtained high accuracy, but it requires a high amount of time which is the main drawback. However, on the other side, automatic segmentation techniques are yet not reliable. Therefore, to overcome these issues, the semi-automatic segmentation techniques are currently being used for clinical applications which are the best way to solve the limitations of automatic segmentation simultaneously. The user initialization is required in several semi-automatic methods to assure the accuracy rate.

*Corresponding Author (sleepl@ changwon.ac.kr) 


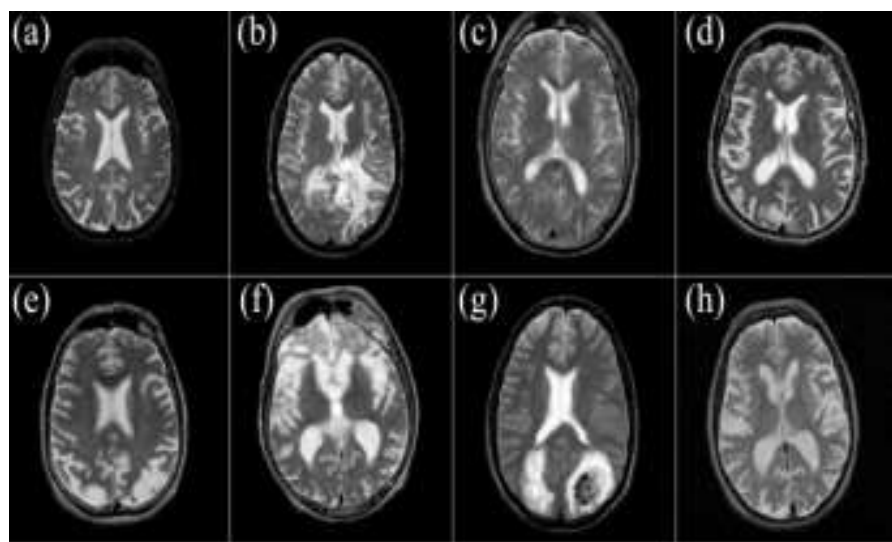

Fig. 1. Different Brain Diseases (a) Normal Brain; (b) Glioma; (c) Meningioma; (d) Alzheimer's Disease; (e) Alzheimer's Disease with Visual

Agnosia; (f ) Pick's Disease; (g) Sarcoma; (h) Huntington's Disease.

The appropriate segmentation of the MR image tumor part improves the efficiency of the techniques. The researcher must have adequate knowledge about the image processing techniques to process different kinds of medical images. Therefore, for this purpose, we have reviewed and critically analyzed different tumor detection techniques in MR images used by various researchers to identify the gaps and limitations.

The structure of the rest of the review paper is as follows: Section 2 presents the Literature Review, Section 3 presents computer vision and image processing, Section 4 presents Critical Analysis of different existed methods, Section 5, presents Discussion and Section 6 presents Conclusion and Future Work.

\section{LITERATURE REVIEW}

In this section the existing techniques of brain tumor segmentation and classification have been discussed. The conventional approach to identify the brain abnormality is manual, which is very prone to misclassify and is time consuming. Therefore, researchers have proposed numerous automated techniques to overcome this issue.

The processing and analyzing of brain tumor MR images are the most challenging task. Different researchers have proposed different techniques to classify the brain tumor in MR images such as support vector (SVM), fuzzy clustering mean (FCM), artificial neural network (ANN), expectationmaximization (EM) and knowledge-based technique algorithm. These mentioned algorithms are the most popular algorithms which are employed for region-based segmentation to extract the required data from MR images. We have critically reviewed some of the proposed techniques to pave the way for further research.

El-Dahsan et. al., [1] proposed a hybrid technique to classify the magnetic resonance images. The proposed algorithm comprised of three stages, such as feature extraction, feature reduction, and classification. In the first stage, Discrete Wavelet Transform (DWT) is employed, then Principal Component Analysis (PCA) is used for feature reduction in the second stage and lastly, in the third stage of the methodology, Feed Forward Back-Propagation Artificial Neural Network (FP-ANN) and k-Nearest Neighbor (k-NN) algorithm are employed for the classification process. A total of 70 (60 abnormal and 10 normal) axial T2-W images were used and achieved $97 \%$ and $98.6 \%$ accuracy on ANN and k-NN algorithm, respectively.

Nazir et al., [2] proposed an automatic approach for brain MRI classification. Three stages have been used in the methodology, such as pre-processing, feature extraction and classification. In the pre-processing step, the median filter is applied for noise removal from the MR image. The color moments are extracted as mean features from the MR images in the feature extraction stage. The feed-forward artificial neural network has been used to classify these extracted features as normal or abnormal. In the proposed methodology, they have used 70 (45 abnormal and 25 normal) T2-W MR images and obtained a $91.8 \%$ accuracy rate.

Lavanyadevi et al. [3], used a neural network to classify the brain tumor phase such as malignant, benign or normal. Gray Level Co-occurrence matrix is used for feature extraction. Principal component analysis has been used for dimensionality reduction while the classification stage of the MR brain image has been done by using a probabilistic neural network and achieved some satisfactory results.

Amin et al., [4] classify the normal and abnormal brain MRI. In the pre-processing stage, the non-cerebral tissues are eliminated from MR images using morphological operation; afterward, the Gaussian filter is applied for noise removal. Then for the feature set, they have chosen texture, shape, and intensity. Finally, the support vector machine is employed to classify the normality and abnormality.

Kumar et. al., [5] presented a hybrid approach for brain tumor detection. For feature extraction and reduction, discrete wavelet transform (DWT) and a genetic algorithm have been used respectively. A support vector machine (SVM) has been employed for the classification of a brain tumor as benign or malignant. A data set of 25 (20 normal and 5 abnormal) T2-W brain MR images were obtained for the SICAS medical image repository. Different parameters have been used for analyzing these images such as root mean square error (RMS), smoothness, and entropy and achieved some satisfactory results.

Iscan et al., [6] mainly focused on tumor detection in MR brain images by finding asymmetry in the right or left brain hemisphere. They have used an incremental supervised neural network for the segmentation of MR images. For image brightness, continuous wavelet transform has been applied. While Zernike is applied for vector representation, this method obtained $100 \%$ accuracy on both normal and abnormal MR image segmentation.

Zhang and $\mathrm{Wu}$ [7] used the wavelet transform for feature extraction from MR images. Principal component analysis has been used for feature reduction. Then these reduced features were sent to the kernel support vector machine. They have selected seven different diseases. 20 normal and 140 abnormal images were collected from Harvard medical school website and achieved some good results.

Fayaz et al., [8] used a three steps algorithm for brain MRI classification such as pre-processing, feature extraction, and 
classification. The median filter is applied to a grayscale MR image for noise removal and then converted this grayscale image to an RGB format in the first stage. The three channels were extracted i.e., red, green and blue from every single channel of RGB in the feature extraction stage, then classified these extracted features as normal or abnormal in the third stage. They have used 100 T2-weighted images (30 abnormal and 70 normal) and obtained some good results.

Zarendi et. al., [9], proposed a method for tumor detection in the brain MR image by using the type-II fuzzy technique. The fuzzy logic has been used in some specific areas to solve the uncertainty about the data classification. Demirhan and Guler [10], have combined stationary wavelet transformation with a self-organization map to segment the MR images. The standard images have been considered from the internet brain segmentation repository (IBSR) and the MRI experts have performed the results of segmentation.

Ibrahim et al., [11], used principal component analysis (PCA) to reduce the dimension of the data. While for the detection of a brain tumor in MR images, the supervised feedforward back-propagation neural network has been used. They have used three layers of ANN such as, i) the input layer which contains 64 neurons ii) hidden layers which comprised of 10 neurons and iii) the output layer which consists of 64 neurons. They have classified the images in four different classes such as normal tissues, Edema, cancerous tissue, and not a classified class. This proposed methodology achieved a $96.33 \%$ accuracy result.

Jafarpour et. al. [12], using the gray level co-occurrence matrix in MR images for feature extraction. The two most essential algorithms were combined in a feature reduction stage to select the best features. Then those features were presented to the artificial neural network and k-nearest neighbor and obtained a $100 \%$ accuracy rate on both normal and abnormal images.

Saha et. al., [15] presented a score based bounding box technique for approximate segmentation from MR brain image. In 2D slices, the MR images were segmented and the region based global change has also been observed. The image tumor part is measured as a change in MRI. The Fast bounding Box technique is used to find the asymmetric region in MR image slices. $92 \%$ accuracy for tumor detection and $89 \%$ accuracy for Edema detection been observed. Węgliński and Fabijańska [17], have used region growing algorithm and extracted the complete abnormal tissue. For separation of the normal and abnormal area, the seed point is employed. The median filter is used for noise removal as it preserves the edges and does not affect the image quality. The methodology produced some satisfactory results. The pre-processing and post-processing stages increase the execution time.

Shanthi and Sasikumar [21] have employed fuzzy logic and neural network algorithm for MR image segmentation. In the image segmentation, they have mainly focused on white matter, gray matter, and cerebrospinal fluid. Fuzzy logic has been used for clustering, and the output of the fuzzy system is presented to the artificial neural network as an input. For the testing purpose, they have considered T1- weighted images.
Shree and Kumar [22] used morphological filtering for noise removal to enhance the MR brain image and used graylevel co-occurrence matrix (GLCM) for feature extraction and discrete wavelet transform (DWT) has been used for feature reduction to reduce the complexity. Lastly, for the detection of tumor location in the MR brain image probabilistic neural network (PNN) classifier has been employed and achieved $100 \%$ and $95 \%$ accuracy rate for training and testing dataset respectively.

Bahadure et al., [23], an automated methodology has been proposed for brain MR image tumor segmentation. The methodology employed Berkeley wavelet transform and SVM for feature extraction and classification, respectively. They obtained $96.51 \%, 94.2 \%$ and $97.72 \%$, accuracy, specificity, and sensitivity, respectively.

\section{COMPUTER VISION AND IMAGE PROCESSING}

The ultimate goal of computer vision is to employ computers to imitate human vision. The image analysis field lies between image processing and computer vision [29]. The high, mid and low-level processes are the general computerized processes. The high-level processing is connected with vision. Whereas, the segmentation and classification lie in mid-level processing. The low-level processing does noise reduction and image contrast enhancement.

The MRI image contained a high amount of information like for instance, the current MRI system can generate images that are equals to 65,535 gray-level [30]. Extracting all the information from this MR image by using human vision is not possible. Because the human eye is unable to differentiate between thousands of gray-levels. Therefore, the use of a computer is the best option to understand and evaluate the high-resolution images in depth.

The classification of brain MRI images follows different stages, such as pre-processing, feature extraction, feature reduction, and classification as shown in Fig. 2. These stages are thoroughly explained in sections below.

\section{A. Pre-Processing}

Different variety of pre-processing methods are applicable for different circumstances such as adaptive, linear, non-linear, multi-scale or pixel-based [31]. The noise appears in the MR image because of the variation of the magnetic field in the coil [32]. The noise, partial volume effect, and shading artifact are generally associated with MR images. There is an essential connection between Signal to Noise Ratio (SNR) and Contrast to Noise Ratio (CNR) in MRI application [33]. For diagnostic purposes, high spatial resolution and high contrast are important. Most of the algorithms are noise sensitive; therefore, a high SNR is mandatory in image processing applications. In this regard, noise filtering techniques are required to apply on MR images to remove the noise and preserve the edges of the image. There are various approaches that have been used to improve the SNR and CNR via wavelet filters, adaptive filters, and anisotropic diffusion filters. Out of these techniques, the anisotropic diffusion filtering method illustrates some good results due to its computational speed and its simplicity. 
Pre-processing

\section{registration, denoising, skull-stripping, intensity normalization}

\section{Feature extraction}

\begin{abstract}
mono-/multi-modal: intensities, textures, edges, alignment
\end{abstract}

\section{Segmentation}

\section{region-based, edge-based, voxel-wise classification/clustering}

\section{Post-processing}

\section{spatial regularization, shape \\ constraints, local constraints}

Fig. 2. Schematic Diagram of Brain MRI Segmentation.

The medical images are affected by different types of noises. The MRI images are spoiled by salt and pepper noise, Gaussian noise, speckle noise, etc. It has been proved that for noise removal from MR image, a median filter is the best choice as a linear filter [34]. The focus on the MR image preprocessing stage is essential before it is fed to the classifier; otherwise, we will get the wrong results [35].

Image enhancement is another step required in the preprocessing stage. The different method has been used in [36] for MR image enhancement such as contrast stretch normalization, histogram stretching, histogram normalization, Gaussian kernel normalization, intensity scaling, and histogram equalization. By comparing the results of these techniques, the histogram normalization technique gives the best performance.

The background of an image does not provide any information, and it also maximizes the computation time [37]. So to decrease memory usage and enhance the processing speed, the skull, scalp, eyes, and background needs to be eliminated. The Brain Surface Extractor in [37],[38] has been used for MRI skull stripping.

\section{B. Feature Extraction}

Feature extraction is the process of converting an image into its group of features. Mostly these techniques are used for feature extraction such as Gabor features, Bag-of-words, texture features, co-occurrence matrix, wavelet transform based features, etc. In [39], discrete wavelet transform and bagof-words techniques are used to extract the features from brain MRI. Recognition of essential features leads us to design an efficient system. With feature extraction, the time, data and memory get decreased [40]. The feature extraction stage is extremely important as the outcome is calculated based on these extracted features data [41]. Efficient feature selection makes accurate feature set by eliminating extra features and also overcome dimensionality issues [42]. Essential features are obtained from brain MR images using Fourier transform, independent component analysis and wavelet transform [43].

Nowadays, most researchers used a combination of spectroscopic or MRS features to discriminate against the type of brain tumor. The MRS features provide precise results as mention in [44]. Some techniques depend on high dimensional features; therefore, high memory storage is required [45]. Fig. 2 illustrates the schematic brain MRI segmentation.

Techniques such as Independent component analysis, linear discriminant analysis, and principal component analysis are used for feature reduction. The combination of feature extraction algorithm with feature reduction algorithm takes us to the perfect system that utilizes limited features which can be extracted with low computational cost [42].

\section{Dimensionality Reduction}

In this stage, the dominant features are selected from the extracted features stage using different techniques such as principal component analysis, independent component analysis, and genetic algorithm. Feature reduction aim's to reduce the size of the dataset and select the essential features to reduce computational time and complexity. Considering all the features of an image badly affect the system accuracy. Hence, to design a robust system to classify the brain MR image accurately is to consciously select the features using appropriate techniques that decrease unimportant information. Because the efficient technique employs a low number of features. However, extensive reduction of features may reduce the system accuracy [47]. Model efficiency is improved by selecting features. Hence avoiding this stage leads us to poor classifier performance [48].

It is also notable from the literature review that the most popular technique for feature reduction is principal component analysis. This technique transforms the input feature space into a lower-dimensional feature space using the eigen vector correlation matrix [49]. In [50], PCA has been used to reduce the extracted feature from 65536 to 1024 features and obtained a high accuracy rate.

Furthermore, the classification accuracy is enhanced using the dimensionality reduction stage. The feature extraction and feature reduction play an essential part in MRI image classification. 


\section{Classification using Supervised Methods}

In this stage, supervised techniques such as ANN, k-NN, SVM, etc. and unsupervised techniques such as Self-organizing maps and k-means techniques are finally used to classify the MRI image into normal or abnormal. The accurately labeled data is used in supervised techniques that are acquired in the training stage so that to determine the class for unlabelled data of the testing phase [55]. The performance of the supervised classifier is better than an unsupervised classifier in terms of the accuracy rate. All these mentioned algorithms require these stages we discussed above to classify an MRI image. However, the Convolutional neural network does not require to follow these mentioned stages as CNN learns its features automatically from the image by using trainable convolutional filters [51]. We have discussed a few classifiers used in different proposed brain MRI classification methodologies:

\section{E. Artificial Neural Network}

In [46] employed ANN for brain tumor segmentation. The proposed algorithm utilized GLCM+GA+NN for feature extraction, feature reduction and classification, respectively. A neural network classifier is used in [52] to classify the MR image into normal or abnormal. The features were extracted using cubic order differentiations whereas, rule technique was employed for feature selection. Two classifiers were used for brain MRI classification namely feed-forward backpropagation network and $\mathrm{k}-\mathrm{NN}$ in [53]. They have extracted the features using discrete wavelet transform and the features were reduced from 1024 to 7 by PCA. Further, in reference, [54] feature extraction task is done by using PCA and MRI image classification is carried out by PNN. A hybrid machine learning approach is used in [56] for brain tumor detection. The proposed methodology comprised of pre-processing, feature extraction, feature reduction and classification. The median filter is used for noise removal, DWT and PCA are used feature extraction and feature reduction respectively. Finally, the feed-forward BPNN is used to find the normality and abnormality of the MRI.

\section{F. K-Nearest Neighbor}

This algorithm is a supervised learning algorithm, and it compares the new unlabelled problem instances directly with the labeled samples in the training set. In [57] k-NN algorithm is employed for brain MRI image classification. In the proposed methodology, the median filter is used in the preprocessing stage for noise removal. The color moments such as mean, variance, and skewness are used for feature extraction. The dataset comprised of 100 brain MRI images in which 70 were normal and 30 were abnormal and obtained reasonable accuracy.

Furthermore, in [58] k-NN is employed to segment dark and light abnormalities in both low background and medium background gray level values in MRI images. The k-NN algorithm is used for brain MRI classification in [65]. DWT is used for feature extraction and PCA is employed for feature reduction. In their proposed methodology, they have measured and compared seven different statistical techniques such as kurtosis, skewness, and specificity etc.

\section{G. Support Vector Machine}

The SVM can represent complex surfaces including radial basis function and polynomials. The largest margin between the two classes is considering the best hyperplane. The data points that are closest to the separating hyperplane are known as support vectors [59], [60]. This algorithm split the image into two different classes and find the best hyperplane to classify the data efficiently. SVM and GA with Gaussian radial basis functions are used in [61] for brain tumor classification and obtained reasonable accuracy. The SVM classifier is used in paper [62] to classify the tumor type and grade. They have also calculated specificity and sensitivity which provide good results. In [63] presents a methodology for brain MRI classification which is comprised of GA, spatial gray level dependence method and SVM, and they obtained a high accuracy rate. The combination of multi-resolution independent component analysis (MICA) and SVM [64] has increased the accuracy rate 2.5 times higher as compare to other ICA based classification.

\section{H. Unsupervised Techniques}

Unsupervised techniques do not require labeled data. The unsupervised algorithms automatically determine the number of classes. These types of algorithms can solve complex problems. Some of the unsupervised algorithms used by different researchers for brain MRI classification are discussed as:

\section{Self-Organizing Maps}

In [66], an automated hybrid self-organizing maps with fuzzy k-means was proposed to identify normal and abnormal MRI image. They have used clustering for the segmentation process. The greedy k-means algorithm in FKM provides faster convergence. This hybrid algorithm exactly identified the dimension of the tumor region. Brain MRI images are classified into normal or abnormal by using neural network SOM and SVM is used in [43] and acquired 94\% and 98\% accuracy for SOM and SVM respectively. Another unsupervised k-means algorithm was implemented in [67] for image segmentation purposes. Partial stretching enhancement is done in the pre-processing step, while median filtering is used for noise removal in the post-processing step and they obtained good segmentation results.

\section{J. K-Means Clustering}

Clustering is an unsupervised method for image classification. There are two different types of clusters i.e. soft clustering and hard clustering. The data point may belong to a cluster or may not in hard clustering and also the clusters do not overlap. Whereas in soft clustering, the clusters can overlap. Therefore, a single data can belong to two or more than two clusters. K-Means and hierarchical clustering are employed for tumorous tissue separation purposes from an MRI image in [68]. The pseudo-color transformation method is applied to the MRI image and then converted this MRI image into an RGB image for feature enhancement. The same methodology is also implemented in [69] and obtained good results. The complete methodology of brain MRI classification has been shown in Fig. 3 and the general brain structure is depicted in Fig. 4. 


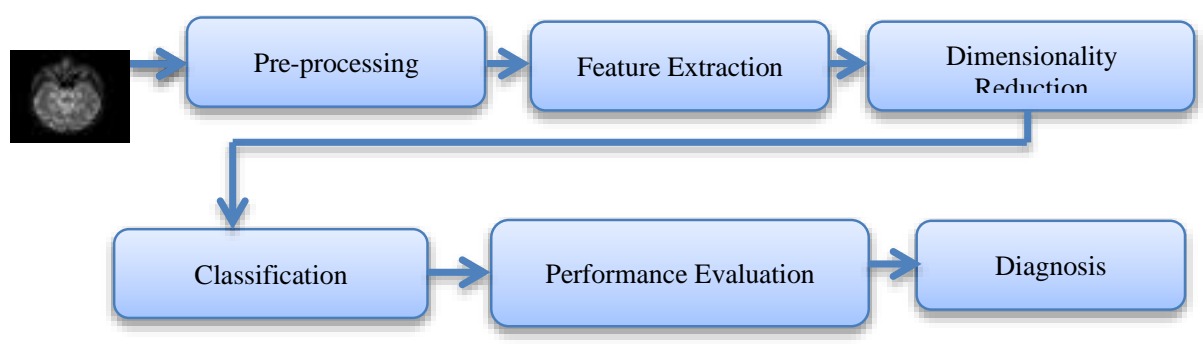

Fig. 3. Methodology of Brain MRI Classification.

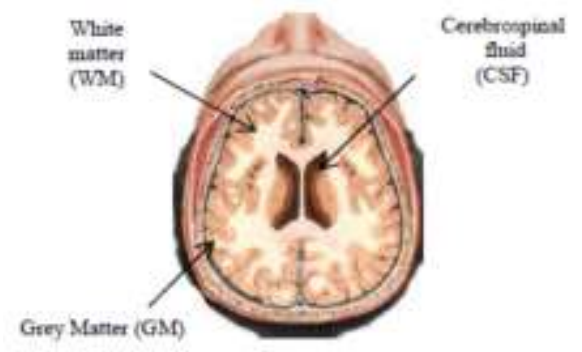

Fig. 4. Brain Image.

\section{CRITICAL ANAlysis}

We have critically reviewed and summarized the literature review part in Table I.

\section{A. Performance Evaluation}

The classification accuracy can be evaluated using several ways. We observed from the literature review that confusion matrix, peak signal to noise ratio, Jaccard Index, Accuracy, Sensitivity, Specificity, and Mean Square Error are the most popular statistical techniques to measure the classifier performance.

TP illustrates - Correctly classified positive instances,

TN illustrates - Correctly classified negative instances,

FP illustrates - Incorrectly classified negative cases, and

FN illustrates - Incorrectly classified positive instances.

- Sensitivity

$$
\text { Sensitivity }=\frac{T P}{T P+F N}
$$

- Specificity

Specificity $=\frac{T N}{T N+F P}$

- Accuracy

$$
\text { Accuracy }=\frac{T P+T N}{T P+T N+F P+F N}
$$

\section{B. Datasets}

For training and testing purpose various, datasets are being used. Such as, BRATS 2012, 2013, 2015, 2016, 2017, 2018 [76-78], Harvard [78], SPL database [79], PGIMER dataset [79], MRBrain S Challenge dataset [80], ISLES 2015 [81], BrainWeb [82], and so on. Different brain tumor datasets are illustrated in Fig. 5 utilized by researchers to validate their methodologies.

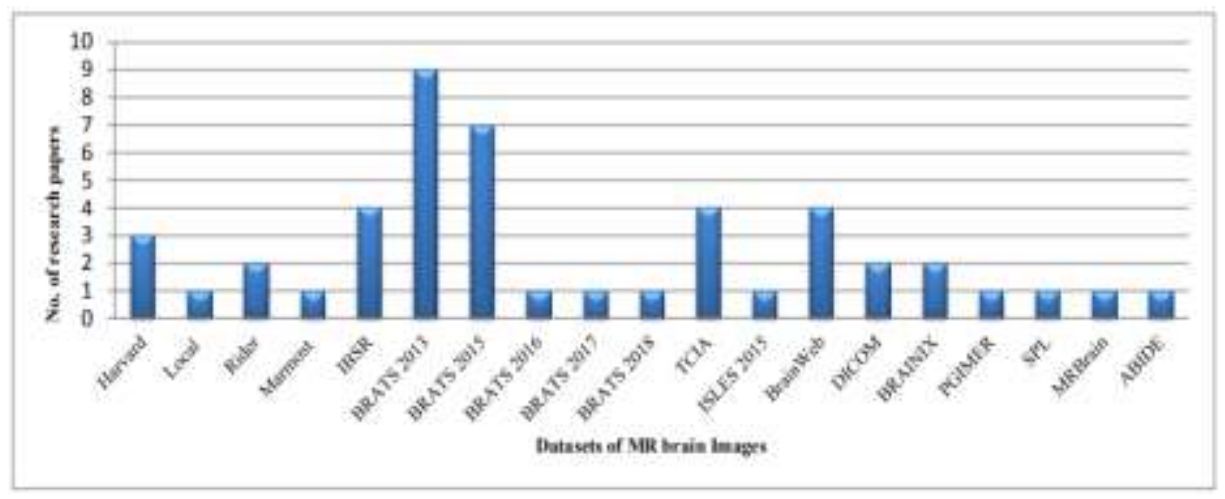

Fig. 5. Depicts Brain MRI Datasets used in Various Publications. 
TABLE. I. CRITICAL ANALYSIS OF DIFFERENT PROPOSED MRI METHODOLOGIES

\begin{tabular}{|c|c|c|c|c|c|}
\hline $\begin{array}{l}\text { Ref- } \\
\text { erences }\end{array}$ & $\begin{array}{l}\text { Focus Area/Feature } \\
\text { Used }\end{array}$ & Algorithm/Technique & Strengths & Limitations & Experimental Results \\
\hline$[1]$ & $\begin{array}{l}\text {-Brain MRI } \\
\text { classification } \\
\text {-A discrete wavelet } \\
\text { transform is used for } \\
\text { feature extraction. }\end{array}$ & $\begin{array}{l}\text {-Discrete wavelet transform } \\
\text {-Principal Component Analysis } \\
\text { (PCA) } \\
\text {-Feedforward back propagation } \\
\text { artificial neural network (FP-ANN) } \\
\text { and k-nearest neighbor(k-NN) }\end{array}$ & $\begin{array}{l}\text { - ANN's physical } \\
\text { implementation is simple } \\
\text { and straightforward. } \\
\text {-The ANN generates } \\
\text { accurate results of } \\
\text { generalization property. } \\
\text { - and can map the } \\
\text { distribution of complex } \\
\text { classes easily. While k- } \\
\text { NN is a suitable choice for } \\
\text { smaller data. }\end{array}$ & $\begin{array}{l}\text {-An extremely } \\
\text { reduction of features } \\
\text { from } 1024 \text { to } 7 \text { may } \\
\text { lose some important } \\
\text { information. }\end{array}$ & $\begin{array}{l}\text {-ANN obtained } 90 \% \\
\text { accuracy. } \\
\text {-k-NN obtained } 99 \% \\
\text { accuracy }\end{array}$ \\
\hline [2] & $\begin{array}{l}\text {-Color moments } \\
\text {-Mean } \\
\text {-Variance } \\
\text {-Skewness }\end{array}$ & $\begin{array}{l}\text { - Artificial neural network } \\
\text {-median filter } \\
\text {-arithmetic mean } \\
\text {-Standard deviation } \\
\text {-Skewness }\end{array}$ & $\begin{array}{l}\text {-The proposed method } \\
\text { obtained good results due } \\
\text { to the simplicity of the } \\
\text { methodology }\end{array}$ & $\begin{array}{l}\text {-The processing time } \\
\text { got increased due to } \\
\text { pre-processing and } \\
\text { post-processing } \\
\text { stages. }\end{array}$ & $\begin{array}{l}\text { - The proposed } \\
\text { methodology } \\
\text { execution time is less } \\
\text { than 20s. }\end{array}$ \\
\hline$[3]$ & $\begin{array}{l}\text {-Brain tumor detection } \\
\text { using Gray level co- } \\
\text { occurrence matrix }\end{array}$ & $\begin{array}{l}\text {-The gray level co-occurrence } \\
\text { matrix } \\
\text {-Principal component analysis } \\
\text {-probabilistic neural network } \\
\text {-K-means clustering }\end{array}$ & $\begin{array}{l}\text {-The probabilistic neural } \\
\text { network quickly learns } \\
\text { from training data and can } \\
\text { adapt its learning in real- } \\
\text { time. }\end{array}$ & $\begin{array}{l}\text {-The computation time } \\
\text { is high due to many } \\
\text { proposed stages. }\end{array}$ & $\begin{array}{l}\text {-The methodology is } \\
\text { robust; however, the } \\
\text { accuracy has not been } \\
\text { mentioned. }\end{array}$ \\
\hline$[4]$ & $\begin{array}{l}\text { - Texture, shape, and } \\
\text { intensity } \\
\text { - The gray level co- } \\
\text { occurrence matrix }\end{array}$ & $\begin{array}{l}\text {-Morphological operation } \\
\text {-Gaussian filter } \\
\text {-Support Vector Machine }\end{array}$ & $\begin{array}{l}\text {-The performance of the } \\
\text { support vector machine is } \\
\text { notable even on large } \\
\text { datasets }\end{array}$ & $\begin{array}{l}\text { - In pre-processing } \\
\text { two steps have been } \\
\text { used such as skull } \\
\text { stripping and noise } \\
\text { removal which } \\
\text { consume extra time }\end{array}$ & $\begin{array}{l}\text {-A total of } 100 \mathrm{MR} \\
\text { images was used in } \\
\text { which } 65 \text { were } \\
\text { abnormal and } 35 \text { were } \\
\text { normal. } \\
\text {-The obtained } \\
\text { accuracy rate is } 97.1 \% \\
\text { - The specificity rate is } \\
98.0 \% \\
\text { - Sensitivity rate is } \\
91.9 \%\end{array}$ \\
\hline$[5]$ & $\begin{array}{l}\text {-Smoothness, entropy, } \\
\text { root mean square error, } \\
\text { correlation, and kurtosis } \\
\text { are the parameters used } \\
\text { in this paper. } \\
\text {-A genetic algorithm is } \\
\text { used for feature } \\
\text { extraction. }\end{array}$ & $\begin{array}{l}\text {-Discrete wavelet transform } \\
\text {-Genetic algorithm } \\
\text { - Principal component analysis } \\
\text {-Support vector machine }\end{array}$ & $\begin{array}{l}\text {-The support vector } \\
\text { machine is a powerful } \\
\text { classification tool and can } \\
\text { be used for both linear and } \\
\text { non-linear data. } \\
\text { - A genetic algorithm is } \\
\text { effective to find the } \\
\text { solution to search and } \\
\text { optimization problems. }\end{array}$ & $\begin{array}{l}\text { Support vector } \\
\text { machine works } \\
\text { effectively, however, } \\
\text { the accuracy of SVM } \\
\text { gets affected on small } \\
\text { datasets }\end{array}$ & $\begin{array}{l}\text {-T2-weighted brain } \\
\text { MR images dataset has } \\
\text { been used which } \\
\text { comprised of } 25 \\
\text { images. } \\
\text { - } 20 \text { normal and } 5 \\
\text { abnormal. } \\
\text { - The accuracy rate is } \\
\text { not clearly mentioned }\end{array}$ \\
\hline$[6]$ & $\begin{array}{l}\text {-Combined the } \\
\text { segmentation method } \\
\text { and mid-sagittal plane } \\
\text { extraction method to } \\
\text { detect tumor and } \\
\text { asymmetry. }\end{array}$ & $\begin{array}{l}\text {-2D continuous wavelet transform } \\
\text {-incremental supervised neural } \\
\text { network } \\
\text {-Zernike moment by the vector } \\
\text { representation } \\
\text {-Euclidean distance. }\end{array}$ & $\begin{array}{l}\text {-The artificial neural } \\
\text { network implementation is } \\
\text { easy and easily map the } \\
\text { complex distribution. } \\
\text { ANN generates efficient } \\
\text { results. }\end{array}$ & $\begin{array}{l}\text {-The Zernike } \\
\text { moment's calculation } \\
\text { is complex. } \\
\text {-The algorithm takes } \\
\text { wrong decisions when } \\
\text { the small asymmetric } \\
\text { differences increase } \\
\text { the value of ND2. }\end{array}$ & $\begin{array}{l}-100 \% \text { accuracy has } \\
\text { been obtained for } 50 \\
\text { normal brain } \mathrm{MR} \\
\text { images and } 20 \\
\text { abnormal brain MR } \\
\text { images. }\end{array}$ \\
\hline [7] & $\begin{array}{l}\text {-Seven common } \\
\text { diseases such as } \\
\text { Meningioma, glioma, } \\
\text { Pick's disease, sarcoma, } \\
\text { Huntington's disease, } \\
\text { Alzheimer's disease, } \\
\text { Alzheimer's disease } \\
\text { plus visual agnosia has } \\
\text { been considered. } \\
\text {-Discrete Wavelet } \\
\text { Transform is employed } \\
\text { for feature extraction }\end{array}$ & $\begin{array}{l}\text {-Discrete Wavelet Transform } \\
\text { (DWT). } \\
\text {-Principal component analysis } \\
\text { (PCA). } \\
\text {-Kernel support vector machine } \\
\text { (KSVM) with GRB kernel. }\end{array}$ & $\begin{array}{l}\text {-The support vector } \\
\text { machine is very effective } \\
\text { for brain MR image } \\
\text { classification. } \\
\text {-The technique is easy in } \\
\text { implementation } \\
\text {-Fast in execution and } \\
\text { accurate in classification. }\end{array}$ & $\begin{array}{l}\text {-The proposed } \\
\text { methodology running } \\
\text { time is very low, but it } \\
\text { requires some huge } \\
\text { memory to run. }\end{array}$ & $\begin{array}{l}\text {-This proposed } \\
\text { methodology achieved } \\
99.38 \% \text { accuracy. } \\
\text { Whereas, the } \\
\text { computation time is } \\
\text { very low. }\end{array}$ \\
\hline$[8]$ & $\begin{array}{l}\text { - MR images } \\
\text { classification } \\
\text {-The grayscale image is } \\
\text { converted to RGB and } \\
\text { calculate each channel } \\
\text { of RGB and extracted } 9\end{array}$ & $\begin{array}{l}\text { - Median filter } \\
\text {-Color features } \\
\text {-Mean, variance and skewness } \\
\text {-k-NN }\end{array}$ & $\begin{array}{l}\text {-The accuracy rate is } \\
\text { better as compare to other } \\
\text { methods. } \\
\text {-The k-NN is efficient for } \\
\text { the smaller dataset. }\end{array}$ & $\begin{array}{l}\text {-The accuracy of k- } \\
\mathrm{NN} \text { gets reduces when } \\
\text { the dataset is large. }\end{array}$ & $\begin{array}{l}\text {-A total of } 100 \text { images } \\
\text { has been used. } \\
-30 \% \text { testing and } 70 \% \\
\text { of training criteria } \\
\text { have been used. } \\
\text {-The accuracy rate for }\end{array}$ \\
\hline
\end{tabular}




\begin{tabular}{|c|c|c|c|c|c|}
\hline & $\begin{array}{l}\text { features using color } \\
\text { moments }\end{array}$ & & & & $\begin{array}{l}\text { normal and abnormal } \\
\text { images during training } \\
\text { and testing is } 98 \% \text { and } \\
95 \% \text { respectively. } \\
\text {-Low computation } \\
\text { time for feature } \\
\text { extraction and } \\
\text { classification. }\end{array}$ \\
\hline [9] & $\begin{array}{l}\text {-Cerebrospinal fluid } \\
\text {-Gray matter } \\
\text {-White matter } \\
\text {-Brain tumor }\end{array}$ & $\begin{array}{l}\text {-Fuzzy filter } \\
\text {-Type-II Probabilistic C-Mean } \\
\text {-Type-II Fuzzy Logic } \\
\text {-Thresholding } \\
\text {-Fuzzy clustering }\end{array}$ & $\begin{array}{l}\text { Type-II fuzzy showed } \\
\text { more effectiveness than } \\
\text { Type-I. }\end{array}$ & $\begin{array}{l}\text {-The proposed } \\
\text { methodology accuracy } \\
\text { rate is low. } \\
\text {-In the pre-processing } \\
\text { stage, the Type-II } \\
\text { fuzzy expert system } \\
\text { needs further } \\
\text { improvement. }\end{array}$ & $\begin{array}{l}-95 \text { total images have } \\
\text { been used. } \\
-79 \text { images were } \\
\text { identified correctly } \\
\text { and } 16 \text { were identified } \\
\text { incorrectly and } \\
\text { obtained a } 78.94 \% \\
\text { accuracy rate. }\end{array}$ \\
\hline$[10]$ & $\begin{array}{l}\text { Multi-resolution } \\
\text { information is used to } \\
\text { differentiate different } \\
\text { tissues. } \\
\text {-By combining } \\
\text { stationary wavelet } \\
\text { transform (SWT) } \\
\text { coefficients and their } \\
\text { statistical features, a } \\
\text { multi-dimensional } \\
\text { feature vector is } \\
\text { formed. }\end{array}$ & $\begin{array}{l}\text {-Anisotropic diffusion filter. } \\
\text {-SWT. } \\
\text {-Spatial filters } \\
\text {-Self-Organization Map (SOM). } \\
\text {-Learning Vector Quantization. } \\
\text {-Internet brain segmentation } \\
\text { repository }\end{array}$ & $\begin{array}{l}\text {-As shown in the result of } \\
\text { splitting texture } \\
\text { information into different } \\
\text { frequency channels, the } \\
\text { SWT is very effective. } \\
\text {-SOM works efficiently } \\
\text { for dividing M x N- } \\
\text { dimensional data into } \\
\text { multiple segments. }\end{array}$ & $\begin{array}{l}\text { - The execution time } \\
\text { increases with the } \\
\text { division of images in } \\
\text { channels. }\end{array}$ & $\begin{array}{l}\text {-The methodology is } \\
\text { effective than manual } \\
\text { segmentation, } \\
\text { however, the accuracy } \\
\text { is not mentioned in the } \\
\text { paper. }\end{array}$ \\
\hline [11] & $\begin{array}{l}\text { Linear correlation } \\
\text { coefficient } \\
\text {-Linear regression } \\
\text {-Four different classes } \\
\text { of images such as } \\
\text { cancer class, edema } \\
\text { class, cancer class, and } \\
\text { non-classified class. } \\
\end{array}$ & $\begin{array}{l}\text {-Principal component analysis } \\
\text {-Gradient Descent with momentum } \\
\text { weight and bias learning function } \\
\text {-Artificial neural network } \\
\text {-Feedforward artificial neural } \\
\text { network }\end{array}$ & $\begin{array}{l}\text {-The artificial neural } \\
\text { network is simple and } \\
\text { easy for classification. } \\
\text {-The proposed method is } \\
\text { fast in execution and easy } \\
\text { in implementation and } \\
\text { efficient in classification. }\end{array}$ & $\begin{array}{l}\text {-For ANN the trainlm } \\
\text { is used as a training } \\
\text { function which is fast, } \\
\text { however, it needs a lot } \\
\text { of memory to run. }\end{array}$ & $\begin{array}{l}\text { - The accuracy rate of } \\
\text { the methodology is } \\
96.33 \% \text {. } \\
\text { - The average } \\
\text { consuming time is } \\
0.2434 \mathrm{~s} \text {. }\end{array}$ \\
\hline [12] & $\begin{array}{l}\text {-Brain MRI } \\
\text { segmentation } \\
\text {-Images of different } \\
\text { diseases have been } \\
\text { considered such as } \\
\text { normal, tumoral and } \\
\text { MS. } \\
\text {-GLCM calculates the } \\
\text { co-occurrence matrix of } \\
\text { each image. } \\
\text {-Mean, variance and } \\
\text { entropy features are } \\
\text { extracted }\end{array}$ & $\begin{array}{l}\text {-The gray level co-occurrence } \\
\text { matrix } \\
\text {-Principal component analysis } \\
\text {-Linear discriminant analysis } \\
\text { (LDA) } \\
\text {-Artificial neural network (ANN) } \\
\text {-k-nearest neighbor (k-NN) }\end{array}$ & $\begin{array}{l}\text {-ANN is simple and also } \\
\text { easy in implementation } \\
\text { While for smaller dataset } \\
\text { k-NN is more efficient } \\
\text {-The accuracy rate of the } \\
\text { proposed methodology is } \\
\text { astounding compared to } \\
\text { the existing methods. }\end{array}$ & $\begin{array}{l}\text {-This technique may } \\
\text { not effective for other } \\
\text { modalities. }\end{array}$ & $\begin{array}{l}\text {-Achieved a } 100 \% \\
\text { accuracy rate for } \\
\text { normal images, } \\
92.86 \% \text { for MS and } \\
100 \% \text { accuracy for } \\
\text { tumoral images with } \\
\text { ANN and k-NN } \\
\text { classifiers. } \\
\text {-The computation time } \\
\text { for feature extraction } \\
\text { and classification is } \\
\text { only } 0.025 \mathrm{~s} \text {. }\end{array}$ \\
\hline [13] & $\begin{array}{l}\text {-Color converted } \\
\text { images } \\
\text {-Differentiate the region } \\
\text { and lesion size }\end{array}$ & $\begin{array}{l}\text {-Thresholding } \\
\text {-color converted segmentation } \\
\text {-k-means clustering algorithm }\end{array}$ & $\begin{array}{l}\text {-Fast and easy for small } \\
\text { data } \\
\text {-The accuracy rate of the } \\
\text { methodology is quite high, } \\
\text { whereas, the computation } \\
\text { time is reasonable. }\end{array}$ & $\begin{array}{l}\text {-k-means clustering is } \\
\text { not effective for the } \\
\text { choice of distance } \\
\text { measure and the initial } \\
\text { cluster assignment. }\end{array}$ & $\begin{array}{l}-100 \% \text { accuracy rate } \\
\text { for MRI T2-w images } \\
\text { and the computation } \\
\text { time is the } 30 \text { s. } \\
-75 \% \text { accuracy rate } \\
\text { for spin density and } \\
\text { computation time is } \\
\text { only } 30 \text { s. } \\
\text {-For T1-w images are } \\
80 \% \text { accuracy rate and } \\
30 \text { s is the computation } \\
\text { time. }\end{array}$ \\
\hline [14] & $\begin{array}{l}\text {-Detection of the mass } \\
\text { tumor } \\
\text {-Shape and range of } \\
\text { brain tumor detection. }\end{array}$ & $\begin{array}{l}\text {-Median filter } \\
\text {-Euclidean distance } \\
\text {-k-mean clustering } \\
\text {-Fuzzy c-mean algorithm }\end{array}$ & $\begin{array}{l}\text {-Fuzzy C-mean algorithm } \\
\text { is accurate than k-means } \\
\text { clustering }\end{array}$ & $\begin{array}{l}\text {-The accuracy rate has } \\
\text { not been shown } \\
\text {-The noise addition } \\
\text { and removal are not } \\
\text { well explained. }\end{array}$ & $\begin{array}{l}\text {-Results have not been } \\
\text { shown clearly. }\end{array}$ \\
\hline$[15]$ & $\begin{array}{l}\text {-Region-based global } \\
\text { change. } \\
\text {-2D MR slices } \\
\text {-The region containing } \\
\text { the tumor is considered }\end{array}$ & $\begin{array}{l}\text { - The fast bounding box (FBB). } \\
\text {-Score function. } \\
\text {-Mean shift clustering (MSC). } \\
\text {-Bhattacharya coefficient. } \\
\text {-Ellipse fitting technique. }\end{array}$ & $\begin{array}{l}\text {-Prior parameter } \\
\text { distribution is not required } \\
\text { for the unsupervised } \\
\text { techniques. } \\
\text {-Image registration is not }\end{array}$ & $\begin{array}{l}\text {-The performance of } \\
\text { FBB is mostly } \\
\text { reduced by noise. } \\
\text {-On MR slice this } \\
\text { method generates a }\end{array}$ & $\begin{array}{l}-92 \% \text { accuracy has } \\
\text { been achieved for } \\
\text { tumor detection and } \\
89 \% \text { for Edema by the } \\
\text { proposed }\end{array}$ \\
\hline
\end{tabular}




\begin{tabular}{|c|c|c|c|c|c|}
\hline & $\begin{array}{l}\text { as a change in the } \\
\text { image. }\end{array}$ & & $\begin{array}{l}\text { required for the fast } \\
\text { bounding box. } \\
\text {-Intensity standardization } \\
\text { is not required in MR } \\
\text { slices. } \\
\text {-The labeled images } \\
\text { training set is not required }\end{array}$ & $\begin{array}{l}\text { box } \\
\text {-The FBB } \\
\text { performance depends } \\
\text { on the asymmetry of } \\
\text { two halves of MR } \\
\text { images. }\end{array}$ & methodology. \\
\hline [16] & $\begin{array}{l}\text {-Eigen Vector. } \\
\text {-Wavelet Coefficients } \\
\text {-Asymmetry in an axial } \\
\text { brain MR images }\end{array}$ & $\begin{array}{l}\text {-Principal component analysis } \\
\text { (PCA) } \\
\text {-Discrete Wavelet Transform } \\
\text { - Artificial neural network } \\
\text {-Levenberg-Marquardt learning } \\
\text { Rule. }\end{array}$ & $\begin{array}{l}\text {-k-NN is efficient for the } \\
\text { smaller dataset and ANN } \\
\text { is simple in } \\
\text { implementation } \\
\text {-The complexity is } \\
\text { removed by PCA. } \\
\text {-Good accuracy rate is } \\
\text { shown by the proposed } \\
\text { methodology. }\end{array}$ & $\begin{array}{l}\text {-From } 1024 \text { to } 7 \text { only, } \\
\text { the features are } \\
\text { reduced which is not } \\
\text { adequate while the } \\
\text { increase in features } \\
\text { badly decreases the } \\
\text { performance of the } \\
\text { system. }\end{array}$ & $\begin{array}{l}\text { k-NN achieved } 99 \% \\
\text { accuracy rate. } \\
\text {-ANN achieved } 90 \% \\
\text { accuracy rate. }\end{array}$ \\
\hline [17] & $\begin{array}{l}\text {-Standard deviation } \\
\text {-Seed point. } \\
\text {-Different pixels } \\
\text { intensity. } \\
\text {-The arithmetic means } \\
\text { of neighbor pixels. }\end{array}$ & $\begin{array}{l}\text {-Arithmetic mean. } \\
\text {-Median filter. } \\
\text {-Standard deviation } \\
\text {-Region growing algorithm. }\end{array}$ & $\begin{array}{l}\text {-Due to the easiness of the } \\
\text { method, the results are } \\
\text { satisfactory. } \\
\text {-The median filter } \\
\text { preserves the image edges. }\end{array}$ & $\begin{array}{l}\text {-The execution time } \\
\text { gets increase with } \\
\text { pre-processing and } \\
\text { post-processing } \\
\text { methods. }\end{array}$ & $\begin{array}{l}\text {-The time of execution } \\
\text { is less than } 20 \mathrm{~s} \text {. } \\
\text {-while the } \\
\text { segmentation } \\
\text { execution time is } 2.9 \mathrm{~s} \text {. }\end{array}$ \\
\hline [18] & $\begin{array}{l}\text {-Image segmentation } \\
\text {-Template based k- } \\
\text { means and modified } \\
\text { fuzzy c-means } \\
\text { clustering (TKFCM) } \\
\text {-Statistical feature and } \\
\text { region-based feature. }\end{array}$ & $\begin{array}{l}\text {-Adaptive threshold } \\
\text {-Histogram imaging } \\
\text {-wiener filter } \\
\text {-median filter } \\
\text {-TKFCM based segmentation. } \\
\text {-Support vector machine } \\
\text {-Artificial neural network back- } \\
\text { propagation }\end{array}$ & $\begin{array}{l}\text {-The SVM classifier } \\
\text { handles both separable } \\
\text { and non-separable } \\
\text { problems. } \\
\text {-First order statistic } \\
\text { features used to determine } \\
\text { brain normality and } \\
\text { abnormality using SVM. } \\
\text {-While ANN is simple in } \\
\text { implementation and is } \\
\text { used to reduce the error } \\
\text { value. } \\
\text {-ANN-BP is used to find } \\
\text { the tumor regions. }\end{array}$ & $\begin{array}{l}\text {-The accuracy rate of } \\
\text { the proposed method } \\
\text { is high but the use of } \\
\text { many techniques leads } \\
\text { to complexity. }\end{array}$ & $\begin{array}{l}\text {-This method achieved } \\
97.37 \% \text { accuracy rate } \\
\text {-Computation time is } 2 \\
\text { min which is quite } \\
\text { high. } \\
\text {-sensitivity and } \\
\text { specificity rate is } 98 \% \\
\text { and } 100 \% \\
\text { respectively. }\end{array}$ \\
\hline [19] & $\begin{array}{l}\text {-Image segmentation } \\
\text {-Discrete Wavelet } \\
\text { Transform (DWT) } \\
\text { DAUB-4 } \\
\text {-T2-W brain MR } \\
\text { images } \\
\text {-Level-4 decomposition } \\
\text { is employed. }\end{array}$ & $\begin{array}{l}\text {-Daubechies (DAUB-4) } \\
\text { - Principal component analysis } \\
\text { (PCA). } \\
\text {-Support vector machine (SVM), } \\
\text { Linear kernel and Radial basis } \\
\text { kernel function (RBF). }\end{array}$ & $\begin{array}{l}\text {-Two types of SVM } \\
\text { kernel have been used. } \\
\text {-The linear kernel does } \\
\text { not perform well due to } \\
\text { the small margin in } \\
\text { feature space. } \\
\text {-Radial basis kernel } \\
\text { function performs well } \\
\text { because support vectors } \\
\text { automatically achieve the } \\
\text { training process part. }\end{array}$ & $\begin{array}{l}\text {-The low selection of } \\
\text { features might lose } \\
\text { important information. } \\
\text {-only } 7 \text { features are } \\
\text { selected per image. } \\
\text {-DAUB-4 is } \\
\text { computationally } \\
\text { expensive. }\end{array}$ & $\begin{array}{l}\text {-A total of } 75 \text { images } \\
\text { of T2-W were used in } \\
\text { which } 10 \text { were normal } \\
\text { and } 65 \text { were abnormal } \\
\text { images. } \\
\text { - } 98.46 \% \text { accuracy } \\
\text { has been achieved } \\
\text { using SVM radial base } \\
\text { function. } \\
\text {-While, SVM linear } \\
\text { base function achieved } \\
94.7 \% \text { accuracy. }\end{array}$ \\
\hline [20] & $\begin{array}{l}\text {-mBm texture features. } \\
\text {-Probability distribution } \\
\text { - Fractal dimension. }\end{array}$ & $\begin{array}{l}\text {-KLD method } \\
\text {-Fractal dimension, level set based } \\
\text { method. } \\
\text {-Expectation maximization } \\
\text { algorithm. } \\
\text {-Graph cut procedure. } \\
\text {-Laplacian matrix. }\end{array}$ & $\begin{array}{l}\text {-For tumor segmentation, } \\
\text { this technique performs } \\
\text { well. } \\
\text {-The advantage of this } \\
\text { method is, it can be } \\
\text { implemented on various } \\
\text { modalities. }\end{array}$ & $\begin{array}{l}\text {-The time is very high } \\
\text { for normalization, } \\
\text { feature extraction, } \\
\text { feature selection, and } \\
\text { segmentation. } \\
\text {-For different } \\
\text { modalities, accuracy is } \\
\text { not provided. }\end{array}$ & $\begin{array}{l}\text {-In this methodology, } \\
249 \text { images of MRI } \\
\text { have been considered. } \\
-100 \% \text { accuracy has } \\
\text { been shown by mBm } \\
\text { features in } \\
\text { multimodalities T1,T2 } \\
\text { and FLAIR MRI } \\
\text { segmentation. }\end{array}$ \\
\hline [21] & $\begin{array}{l}\text { Detection of volume } \\
\text { changes in brain tissues }\end{array}$ & $\begin{array}{l}\text {-Fuzzy C-Means Algorithm. } \\
\text {-Artificial neural network } \\
\text {-High pass and low pass filter } \\
\text {-Mean and standard deviation. }\end{array}$ & $\begin{array}{l}\text {-The number of iteration } \\
\text { is decreased and the pixels } \\
\text { are classified into one } \\
\text { group. }\end{array}$ & $\begin{array}{l}\text {-NN requires a huge } \\
\text { amount of data and } \\
\text { time for training. } \\
\text {-Its computation is } \\
\text { complex. }\end{array}$ & $\begin{array}{l}\text {-The computation time } \\
\text { is reasonable. }\end{array}$ \\
\hline [22] & $\begin{array}{l}\text {-Discrete wavelet } \\
\text { transform (DWT) is } \\
\text { used to extract wavelet } \\
\text { coefficients } \\
\text {-Gray level co- } \\
\text { occurrence matrix is } \\
\text { used for statistical } \\
\text { feature extraction. } \\
\text {-image segmentation. }\end{array}$ & $\begin{array}{l}\text {-Morphological operation. } \\
\text {-DWT } \\
\text {-GLCM } \\
\text {-Probabilistic neural network }\end{array}$ & $\begin{array}{l}\text {-The method is easy in } \\
\text { implementation, the } \\
\text { accuracy rate is } \\
\text { satisfactory. } \\
\text { - The methodology of } \\
\text { tumor detection and } \\
\text { identification of location } \\
\text { rate are quite speedy. } \\
\text {-The probabilistic neural }\end{array}$ & $\begin{array}{l}\text {-The computation time } \\
\text { is high due to many } \\
\text { proposed stages. }\end{array}$ & $\begin{array}{l}-100 \% \text { accuracy rate is } \\
\text { achieved for the } \\
\text { training dataset } \\
\text {-As from LL and HL, } \\
\text { the statistical features } \\
\text { were extracted. } \\
\text {-While } 95 \% \text { accuracy } \\
\text { rate is achieved for } \\
\text { testing dataset. }\end{array}$ \\
\hline
\end{tabular}




\begin{tabular}{|c|c|c|c|c|c|}
\hline & & & $\begin{array}{l}\text { network quickly learns } \\
\text { from training data and can } \\
\text { adapt its learning in real- } \\
\text { time. }\end{array}$ & & \\
\hline [23] & $\begin{array}{l}\text {-Segmented White } \\
\text { matter, gray matter, } \\
\text { cerebrospinal fluid, and } \\
\text { tumor tissues. } \\
\text {-Gray level co- } \\
\text { occurrence matrix. } \\
\text {-Tumor detection. }\end{array}$ & $\begin{array}{l}\text {-Berkeley wavelet transform } \\
\text { (BWT) } \\
\text {-Morphological operation. } \\
\text {-Gray level Co-occurrence matrix } \\
\text { (GLCM). } \\
\text {-Support vector machine. }\end{array}$ & $\begin{array}{l}\text {-The method is robust and } \\
\text { obtained a good accuracy } \\
\text { rate. } \\
\text {-Significant for brain } \\
\text { tumor detection. } \\
\text {-Classification accuracy is } \\
\text { not mentioned }\end{array}$ & $\begin{array}{l}\text { - Support vector } \\
\text { machine works } \\
\text { effectively; however, } \\
\text { the accuracy of SVM } \\
\text { gets affected on small } \\
\text { datasets. }\end{array}$ & $\begin{array}{l}\text {-T1-W, T2-W and } \\
\text { FLAIR images were } \\
\text { used. } \\
\text {-Total } 96.51 \% \\
\text { accuracy was obtained } \\
\text { as identifying normal } \\
\text { and abnormal tissue } \\
\text { from the MR images. }\end{array}$ \\
\hline$[71]$ & $\begin{array}{l}\text { Deep neural network } \\
(\mathrm{DNN})\end{array}$ & $\begin{array}{l}\text { No need for pre-processing, feature } \\
\text { extraction and feature reduction }\end{array}$ & $\begin{array}{l}\text { Efficiently extracted the } \\
\text { complex feature } \\
\text {-Less outlier compare to } \\
\text { other suggested } \\
\text { methodologies }\end{array}$ & $\begin{array}{l}\text {-Post-processing } \\
\text { implementation is } \\
\text { required }\end{array}$ & $\begin{array}{l}\text { BRATS2013 dataset } \\
\text { was used while the } \\
\text { accuracy is not } \\
\text { mentioned. }\end{array}$ \\
\hline$[72]$ & Based on fully $\mathrm{CNN}$ & $\begin{array}{l}\text { Dice loss, bootstrapping loss, and } \\
\text { sensitivity }\end{array}$ & $\begin{array}{l}\text { Shows powerful and } \\
\text { effective classification as } \\
\text { compared to the original } \\
\text { design of CNN }\end{array}$ & $\begin{array}{l}\text { The ratio of false- } \\
\text { positive prediction is } \\
\text { high in image } \\
\text { classification } \\
\text {-Also, require high } \\
\text { memory storage }\end{array}$ & $\begin{array}{l}\text {-the accuracy rate is } \\
\text { not mentioned }\end{array}$ \\
\hline [73] & Pre-trained CNN & ResNet34 & $\begin{array}{l}\text { Shows powerful and } \\
\text { effective classification }\end{array}$ & $\begin{array}{l}\text { Require high memory } \\
\text { storage }\end{array}$ & $\begin{array}{l}\text { Achieved } 100 \% \\
\text { accuracy }\end{array}$ \\
\hline [74] & Stationary WT & $\mathrm{SWT}+\mathrm{GCNN}$ & -- & $\begin{array}{l}\text { Post-processing is } \\
\text { required }\end{array}$ & $\begin{array}{l}\text { Obtained } 98.6 \% \\
\text { accuracy }\end{array}$ \\
\hline$[75]$ & Tumor segmentation & $\begin{array}{l}\text { Multi-cascade CNN and } \\
\text { Conditional random fields }\end{array}$ & -- & $\begin{array}{l}\text { High memory storage } \\
\text { is required }\end{array}$ & $\begin{array}{l}\text { Obtained } 88.24 \% \\
\text { accuracy }\end{array}$ \\
\hline
\end{tabular}

\section{DISCUSSION}

We have observed from our literature review that most of the researchers focused on automatic methods. The median filter is extensively used in the pre-processing stage because the brain MRI images are mostly effected by salt and pepper noise. DWT and GLCM are the most used techniques for feature extraction. Principal component analysis and genetic algorithm are widely used for feature reduction. Lastly, the classification of brain MRI image task was mostly performed by using ANN, K-NN, SVM, and SOM. We have also observed from our literature review that $\mathrm{CNN}$ based algorithms provide some good results.

CNN acts differently from other classifiers. CNN learns its features automatically from an image, and there is no need to use the feature extraction or feature reduction stages to feed the features to $\mathrm{CNN}[70]$.

We have critically analyzed and reviewed different proposed MRI classification methods which pave the way for further research in this area which is the main contribution of this work.

\section{CONCLUSION AND FUTURE WORK}

The aim of this article is to retrospect the current trends in brain MRI classification. In this study, brain MR images have been used and proposed different methodologies by different researchers to classify the brain MR images into normal such as (gray matter, white matter, cerebrospinal fluid) and abnormal tissues such as (tumor infected tissues). Most researchers have used four stages to classify the brain MR image such as Pre-processing, Feature extraction, Feature reduction, and Classification. In pre-processing the noise is removed from the brain MR image by using a median filter mostly, as this filter removes the noise from MR image efficiently and preserves the edges effectively, as well as improving the quality of the image for further processing. The feature extraction is the second stage in which the important suitable features in the MR image are identified to detect the brain tumor. Most of the researchers have used a discrete wavelet transform (DWT) and Gray level co-occurrence matrix. The third stage is feature reduction, where the dimensionality of data is reduced to get the most favorable features from the image and in this stage mostly, principal component analysis has been used. The fourth and last stage is, classification of brain MR image as normal or abnormal and in this case, artificial neural network (ANN), k-nearest neighbor (k-NN) and support vector (SVM) have been used. In this paper, we have analyzed that still profound improvements are required in the segmentation and accuracy of MR image processing techniques. As we discussed in the literature that previous proposed techniques comprised of some serious shortcomings such as execution time and the accuracy of abnormality detection that needs to be solved. So, in this case, principal component analysis (PCA) which is a statistical technique used in data analysis is the best option to overcome these limitations.

\section{CONFLICT OF INTEREST}

The authors declare that they have no conflict of interest regarding the publication of this article.

\section{ACKNOWLEDGMENTS}

We are grateful to Department of Computer Engineering, Changwon National University for the immense support in piloting this review. This work was supported by the National Research Foundation of Korea (NRF) grant funded by the Korea government (MSIT) (No. 2018R1C1B6008187). 


\section{REFERENCES}

[1] E. S. A. El-Dahshan, T. Hosny, and A. B. M. Salem, "Hybrid intelligent techniques for MRI brain images classification," Digit. Signal Process. A Rev. J., vol. 20, no. 2, pp. 433-441, 2010.

[2] M. Nazir, F. Wahid, and S. Ali Khan, "A simple and intelligent approach for brain MRI classification,” J. Intell. Fuzzy Syst., vol. 28, no. 3, pp. 1127-1135, 2015.

[3] R. Lavanyadevi, M. MacHakowsalya, J. Nivethitha, and A. Niranjil Kumar, "Brain tumor classification and segmentation in MRI images using PNN," Proc. - 2017 IEEE Int. Conf. Electr. Instrum. Commun. Eng. ICEICE 2017, vol. 2017-Decem, pp. 1-6, 2017.

[4] J. Amin, M. Sharif, M. Yasmin, and S. L. Fernandes, "A distinctive approach in brain tumor detection and classification using MRI," Pattern Recognit. Lett., vol. 0, pp. 1-10, 2017.

[5] S. Kumar, C. Dabas, and S. Godara, "Classification of Brain MRI Tumor Images: A Hybrid Approach,” Procedia Comput. Sci., vol. 122, pp. 510-517, 2017.

[6] Z. Iscan, Z. Dokur, and T. Ölmez, "Tumor detection by using Zernike moments on segmented magnetic resonance brain images," Expert Syst. Appl., vol. 37, no. 3, pp. 2540-2549, 2010.

[7] Y.-D. Zhang and L. Wu, "An Mr Brain Images Classifier via Principal Component Analysis and Kernel Support Vector Machine," Progress In Electromagnetics Research, Vol. 130, pp. 369-388, 2012.

[8] M. Fayaz, A. S. Shah, F. Wahid, and A. Shah, "A Robust Technique of Brain MRI Classification using Color Features and K-Nearest Neighbors Algorithm," Int. J. Signal Process. Image Process. Pattern Recognit., vol. 9, no. 10, pp. 11-20, 2016.

[9] M. H. Fazel Zarandi, M. Zarinbal, and M. Izadi, "Systematic image processing for diagnosing brain tumors: A Type-II fuzzy expert system approach,” Appl. Soft Comput. J., vol. 11, no. 1, pp. 285-294, 2011.

[10] A. Demirhan and I. Güler, "Combining stationary wavelet transform and self-organizing maps for brain MR image segmentation," Eng. Appl. Artif. Intell., vol. 24, no. 2, pp. 358-367, 2011.

[11] W. H. Ibrahim, A. A. A. Osman, and Y. I. Mohamed, "MRI brain image classification using neural networks," Proc. - 2013 Int. Conf. Comput. Electr. Electron. Eng. 'Research Makes a Differ. ICCEEE 2013, pp. 253-258, 2013.

[12] S. Jafarpour, Z. Sedghi, and M. C. Amirani, "A Robust Brain MRI Classification with GLCM Features,” Int. J. Comput. Appl., vol. 37, no. 12, pp. 975-8887, 2012.

[13] L. H. Juang and M. N. Wu, "MRI brain lesion image detection based on color-converted K-means clustering segmentation,” Meas. J. Int. Meas. Confed., vol. 43, no. 7, pp. 941-949, 2010.

[14] J. Selvakumar, A. Lakshmi, and T. Arivoli, "Brain tumor segmentation and its area calculation in brain MR images using K-mean clustering and Fuzzy C-mean algorithm," IEEE-International Conf. Adv. Eng. Sci. Manag. ICAESM-2012, pp. 186-190, 2012.

[15] B. N. Saha, N. Ray, R. Greiner, A. Murtha, and H. Zhang, "Quick detection of brain tumors and edemas: A bounding box method using symmetry," Comput. Med. Imaging Graph., vol. 36, no. 2, pp. 95-107, 2012.

[16] N. H. Rajini and R. Bhavani, "Classification of MRI brain images using k-nearest neighbor and artificial neural network," Int. Conf. Recent Trends Inf. Technol. ICRTIT 2011, pp. 863-868, 2011.

[17] T. Węgliński and A. Fabijańska, "Brain Tumor Segmentation from MRI Data Sets Using Region Growing Approach.” In proc. of 2011 VIIth International Conference on Perspective Technologies and Methods in MEMS Design (MEMSTECH), pp. 185-188, May 11-14, 2011.

[18] R. Ahmmed, A. Sen Swakshar, M. F. Hossain, and M. A. Rafiq, "Classification of tumors and it stages in brain MRI using support vector machine and artificial neural network," ECCE 2017 - Int. Conf. Electr. Comput. Commun. Eng., pp. 229-234, 2017.
[19] M. Ahmad, "Classification of Tumors in Human Brain MRI using Wavelet and Support Vector Machine," IOSR J. Comput. Eng., vol. 8, no. 2, pp. 25-31, 2012.

[20] S. Ahmed, K. M. Iftekharuddin, R. J. Ogg, and F. H. Laningham, "Efficacy of texture, shape, and intensity features for robust posteriorfossa tumor segmentation in MRI," Med. Imaging 2009 Comput. Diagnosis, vol. 7260, no. February, p. 726020, 2009.

[21] K.J. Shanthi, M.N. Sasikumar and C. Kesavadas, "Neuro-fuzzy approach toward segmentation of brain MRI based on intensity and spatial distribution," Jour. Of Med. Imaging and Radiation Sciences, Vol. 41, no. 2, pp. 66-71, 2010.

[22] N. Varuna Shree and T. N. R. Kumar, "Identification and classification of brain tumor MRI images with feature extraction using DWT and probabilistic neural network," Brain Informatics, vol. 5, no. 1, pp. 2330, 2018.

[23] N. B. Bahadure, A. K. Ray, and H. P. Thethi, "Image Analysis for MRI Based Brain Tumor Detection and Feature Extraction Using Biologically Inspired BWT and SVM,” Int. J. Biomed. Imaging, vol. 2017, 2017.

[24] D. N. Louis et al., "The 2016 World Health Organization Classification of Tumors of the Central Nervous System: a summary," Acta Neuropathol., vol. 131, no. 6, pp. 803-820, 2016.

[25] S. J. Choi, J. S. Kim, J. H. Kim, S. J. Oh, J. G. Lee, C. J. Kim, Y. S. Ra, J. S Yeo, J. S Ryu, D. H. Moon, "[18F] 3-deoxy-3-fluorothymidine PET for the diagnosis and grading of brain tumors," European journal of nuclear medicine and molecular imaging, vol. 32, no. 6, pp. 653-659, 2005.

[26] M. Computing, "Image Segmentation for Tumor Detection," vol. 2, no. May, pp. 244-248, 2013.

[27] B. Dong, A. Chien, and Z. Shen, "Frame based segmentation for medical images," Commun. Math. Sci., vol. 9, no. 2, pp. 551-559, 2011.

[28] J. Patel and K. Doshi, "A Study of Segmentation Methods for Detection of Tumor in Brain MRI," Adv. Electron. Electr. Eng., vol. 4, no. 3, pp. 279-284, 2014.

[29] R.C. Gonzalez, R.E. Woods, "Digital Image Processing, second ed., Prentice Hall, New Jersey," 2002.

[30] A. Ortiz, J. M. Górriz, J. Ramírez, D. Salas-González, and J. M. LlamasElvira, "Two fully-unsupervised methods for MR brain image segmentation using SOM-based strategies," Appl. Soft Comput. J., vol. 13, no. 5, pp. 2668-2682, 2013.

[31] I. N. Bankman, Handbook of Medical Imaging, Processing and Analysis, Academic Press, CA, 2000

[32] K. S. Thara and K. Jasmine, "Brain Tumour Detection in MRI Imagesusing PNN andGRNN,” 2016 Int. Conf. Wirel. Commun. Signal Process. Netw., pp. 1504-1510, 2016.

[33] M. G. Ballanger, E. Biglieri, S. Furui, Y. F. Huang, N. Jayant, A. K. Katsagglelos, M. Kaveh, P. K. R. Rajasekaran, J. A. Sorenson, Signal Processing and Communications, Taylor, \& Francis, Boca Raton, 2005.

[34] E. Abdel-Maksoud, M. Elmogy, and R. Al-Awadi, "Brain tumor segmentation based on a hybrid clustering technique," Egypt. Informatics J., vol. 16, no. 1, pp. 71-81, 2015.

[35] N. Nabizadeh and M. Kubat, "Brain tumors detection and segmentation in MR images: Gabor wavelet vs. statistical features," Comput. Electr. Eng., vol. 45, pp. 286-301, 2015.

[36] M. Havaei, P. M. Jodoin, and H. Larochelle, "Efficient interactive brain tumor segmentation as within-brain kNN classification," Proc. - Int. Conf. Pattern Recognit., pp. 556-561, 2014.

[37] N. Nabizadeh and M. Kubat, "Brain tumors detection and segmentation in MR images: Gabor wavelet vs. statistical features," Comput. Electr. Eng., vol. 45, pp. 286-301, 2015.

[38] K. Somasundaram and T. Kalaiselvi, "Fully automatic brain extraction algorithm for axial T2-weighted magnetic resonance images," Comput. Biol. Med., vol. 40, no. 10, pp. 811-822, 2010. 
[39] W. Ayadi, W. Elhamzi, I. Charfi, and M. Atri, "A hybrid feature extraction approach for brain MRI classification based on Bag-ofwords," Biomed. Signal Process. Control, vol. 48, pp. 144-152, 2019.

[40] M. M. Subashini, S. K. Sahoo, V. Sunil, and S. Easwaran, "A noninvasive methodology for the grade identification of astrocytoma using image processing and artificial intelligence techniques," Expert Syst. Appl., vol. 43, pp. 186-196, 2016.

[41] S. L. Jui et al., "Brain MRI Tumor Segmentation with 3D Intracranial Structure Deformation Features," IEEE Intell. Syst., vol. 31, no. 2, pp. 66-76, 2016.

[42] E. A. S. El-Dahshan, H. M. Mohsen, K. Revett, and A. B. M. Salem, "Computer-aided diagnosis of human brain tumor through MRI: A survey and a new algorithm," Expert Syst. Appl., vol. 41, no. 11, pp. 5526-5545, 2014.

[43] S. Chaplot, L. M. Patnaik, and N. R. Jagannathan, "Classification of magnetic resonance brain images using wavelets as input to support vector machine and neural network," Biomed. Signal Process. Control, vol. 1, no. 1, pp. 86-92, 2006.

[44] P. Georgiadis et al., "Improving brain tumor characterization on MRI by probabilistic neural networks and non-linear transformation of textural features," Comput. Methods Programs Biomed., vol. 89, no. 1, pp. 2432, 2008.

[45] M. Havaei, P. M. Jodoin, and H. Larochelle, "Efficient interactive brain tumor segmentation as within-brain kNN classification," Proc. - Int. Conf. Pattern Recognit., pp. 556-561, 2014.

[46] M. Sharma, and S. Mukharjee, "Brain Tumor Segmentation using hybrid Genetic Algorithm and Artificial Neural Network Fuzzy Inference System (ANFIS)," Int. J. Fuzzy Log. Syst., vol. 2, no. 4, pp. 31-42, 2012.

[47] M. Havaei, A. Davy, D. Warde-Farley, A. Biard, A. Courville, Y. Bengio, C. Pal, P.M. Jodoin, H. Larochelle, "Brain tumor segmentation with Deep Neural Networks," Med. Image Anal., vol. 35, pp. 18-31, 2017.

[48] S. Roy, S. Sadhu, S. K. Bandyopadhyay, D. Bhattacharyya, and T. H. Kim, "Brain tumor classification using adaptive neuro-fuzzy inference system from MRI," Int. J. Bio-Science Bio-Technology, vol. 8, no. 3, pp. 203-218, 2016.

[49] K. A. Smitha, A. K. Gupta, and R. S. Jayasree, "Relative percentage signal intensity recovery of perfusion metrics-an efficient tool for differentiating grades of glioma," Br. J. Radiol., vol. 88, no. 1052, 2015.

[50] Y. Zhang and L. Wu, "An MR brain images classifier via principal component analysis and kernel support vector machine," Prog. Electromagn. Res., vol. 130, no. June, pp. 369-388, 2012.

[51] A. Işin, C. Direkoğlu, and M. Şah, "Review of MRI-based Brain Tumor Image Segmentation Using Deep Learning Methods," Procedia Comput. Sci., vol. 102, no. August, pp. 317-324, 2016.

[52] T. Akila and P. UmaMaheswari, "Comparative analysis of classifier performance on MR brain images," Int. Arab J. Inf. Technol., vol. 12, no. 6 A, pp. 772-779, 2015.

[53] B. Sudha, P. Gopikannan, A. Shenbagarajan, C. Balasubramanian, "Computers and Software (IRECOS)," Int. Rev. Comput. Softw., vol. 9, no. 4, 2014.

[54] S. B.Gaikwad and M. S. Joshi, "Brain Tumor Classification using Principal Component Analysis and Probabilistic Neural Network," Int. J. Comput. Appl., vol. 120, no. 3, pp. 5-9, 2015.

[55] N. Gordillo, E. Montseny, and P. Sobrevilla, "State of the art survey on MRI brain tumor segmentation," Magn. Reson. Imaging, vol. 31, no. 8, pp. 1426-1438, 2013.

[56] E. A. S. El-Dahshan, H. M. Mohsen, K. Revett, and A. B. M. Salem, "Computer-aided diagnosis of human brain tumor through MRI: A survey and a new algorithm," Expert Syst. Appl., vol. 41, no. 11, pp. 5526-5545, 2014.
[57] M. Fayaz, A. S. Shah, F. Wahid, and A. Shah, "A Robust Technique of Brain MRI Classification using Color Features and K-Nearest Neighbors Algorithm,” Int. J. Signal Process. Image Process. Pattern Recognit., vol. 9, no. 10, pp. 11-20, 2016.

[58] N. Elaiza, A. Khalid, S. Ibrahim, and U. T. Mara, "MRI Brain Abnormalities Segmentation using," vol. 3, no. 2, pp. 980-990, 2011.

[59] C. J. C. Burges and B. Schölkopf, "Improving the accuracy and speed of support vector machine," Adv. Neural Inf. Process. Syst., no. June, pp. 375-381, 1997.

[60] D. Decoste and B. Schölkopf, "Training invariant support vector machines," Mach. Learn., vol. 46, no. 1-3, pp. 161-190, 2002.

[61] E. I. Zacharaki et al., "MRI-based classification of brain tumor type and grade using SVM-RFE," Proc. - 2009 IEEE Int. Symp. Biomed. Imaging From Nano to Macro, ISBI 2009, pp. 1035-1038, 2009.

[62] H. Selvaraj, S. Thamarai Selvi, D. Selvathi \& L. Gewali, "Brain MRI Slices Classification Using Least Squares Support Vector Machine," International Journal of Intelligent Computing in Medical Sciences \& Image Processing, 1:1, pp. 21-33, 2007.

[63] Ahmed Kharrat, Karim Gasmi, Mohamed Ben Messaoud, Nacéra Benamrane, and and Mohamed Abid, "A Hybrid approach for automatic classification of brain MRI using genetic algorithm and support vector machine," Leonardo J. Sci., vol. 9, no. 17, pp. 71-82, 2010.

[64] S. Sindhumol and K. Balakrishnan, "Abnormality Detection from Multispectral Brain MRI using Multiresolution Independent Component Analysis," vol. 6, no. 1, pp. 177-190, 2013.

[65] V. S. Takate and P. S. Vikhe, "Classification of MRI Brain Images using K-NN and k-means," no. 2, pp. 55-58, 2012.

[66] G. Vishnuvarthanan, M. P. Rajasekaran, P. Subbaraj, and A. Vishnuvarthanan, "An unsupervised learning method with a clustering approach for tumor identification and tissue segmentation in magnetic resonance brain images," Appl. Soft Comput. J., vol. 38, pp. 190-212, 2016.

[67] N. Dhanachandra, K. Manglem, and Y. J. Chanu, "Image Segmentation Using K-means Clustering Algorithm and Subtractive Clustering Algorithm," Procedia Comput. Sci., vol. 54, pp. 764-771, 2015.

[68] M. N. Wu, C. C. Lin, and C. C. Chang, "Brain tumor detection using color-based K-means clustering segmentation," Proc. - 3rd Int. Conf. Intell. Inf. Hiding Multimed. Signal Process. IIHMSP 2007., vol. 2, no. December 2007, pp. 245-248, 2007.

[69] L. H. Juang and M. N. Wu, "MRI brain lesion image detection based on color-converted K-means clustering segmentation," Meas. J. Int. Meas. Confed., vol. 43, no. 7, pp. 941-949, 2010.

[70] Y. Pan et al., "Brain tumor grading based on Neural Networks and Convolutional Neural Networks," Proc. Annu. Int. Conf. IEEE Eng. Med. Biol. Soc. EMBS, vol. 2015-November, pp. 699-702, 2015.

[71] M. Havaei et al., "Brain tumor segmentation with Deep Neural Networks," Med. Image Anal., vol. 35, pp. 18-31, 2017.

[72] J. Zhang, X. Shen, T. Zhuo, and H. Zhou, "Brain Tumor Segmentation Based on Refined Fully Convolutional Neural Networks with A Hierarchical Dice Loss," 2017.

[73] M. Talo, U. B Baloglu, Ö. Yıldırım, U. Rajendra Acharya, “Application of deep transfer learning for automated brain abnormality classification using MR images," Cognitive Systems Research, 54, pp. 176-188, 2019.

[74] M. Mittal, L. Mohan Goyal, S. Kaur, I. Kaur, Amit Verma, D. Jude Hemanth, "Deep learning based enhanced tumor segmentation approach for MR brain images," Applied Soft Computing, 78, pp. 346-354, 2019.

[75] K. Hu, Q. Gan,Y. Zhang, S. Deng, F. Xiao, W. Huang, C. Cao and X. Gao, "Brain Tumor Segmentation Using MultiCascaded Convolutional Neural Networks and Conditional Random Field," IEEE Access,7, pp. 92615-92629, 2019. 
[76] T. M. Mohammed, K. K. Pradeep Mohan, Murugan, B. S., Dhanasekeran, S., Vijayakarthick, P., Selvi, A. Senthil, "Brain Tumor Segmentation Using Convolutional Neural Networks in MRI Images," Journal of Medical Systems, 43 (9), pp. 294, 2019.

[77] K. Hu, Q. Gan,Y. Zhang, S. Deng, F. Xiao, W. Huang, C. Cao and X. Gao, "Brain Tumor Segmentation Using Multi Cascaded Convolutional Neural Networks and Conditional Random Field," IEEE Access,7, pp. 92615-92629. 2019.

[78] X. Zhao, Y. Wu, G. Song, Z. Li, Y. Zhang, Y. Fan, "A deep learning model integrating FCNNs and CRFs for brain tumor segmentation," Medical Image Analysis, 43, (2018), pp. 98-111.

[79] T. Chithambaram and K. Perumal, Brain tumor segmentation using genetic algorithm and ANN techniques, IEEE International Conference on Power, Control, Signals and Instrumentation Engineering (ICPCSI), Chennai, pp. 970-982, 2017.

[80] J. Li, Z. Liang Yu, Z. Gu, H. Liu, Y. Li, "MMAN: Multi-modality aggregation network for brain segmentation from MR images," Neurocomputing, 358, pp. 10-19, 2019.

[81] K. Kamnitsas, C. Ledig, V. F.J. Newcombe, J. P. Simpson, A. D. Kane, D. K. Menon, D. Rueckert, B. Glocker, "Efficient multi-scale 3D CNN with fully connected CRF for accurate brain lesion segmentation," Medical Image Analysis, 36, pp. 61-78, 2017.

[82] E. Abdel-Maksoud, M. Elmogy, R. Al-Awadi, "Brain tumor segmentation based on a hybrid clustering technique," Egyptian Informatics Journal,16 (1), pp. 71-81, 2015.

\section{AUTHOR'S PROFILE}

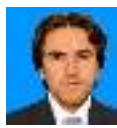

Zahid Ullah, is currently doing Ph.D in Computer Engineering from Changwon National University South Korea. $\mathrm{He}$ received MS in Computer Science from SZABIST, Islamabad, Pakistan in 2015, and BS in Information Technology from University of Malakand Pakistan in 2011. His area of interest are Image Processing and Machine Learning Techniques.

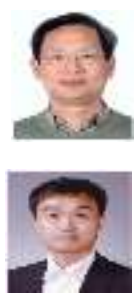

Dr. Su-Hyun, Lee, is working as Professor and Head of department of Computer Engineering, at Changwon National University South Korea. He is working in multiple desciplines, especially Bio-Informatics, Algorithm, and Programming.

Dr. Donghyeok An received the B.S. degree in computer science from Handong University, Pohang, South Korea, in 2006, and the Pd. D. degree in Computer Science from Korea Advanced Institute of Science and Technology (KAIST) in Feb. 2013. He was a post doctor and a visiting professor at Sungkyunkwan University from Mar. 2013 to Feb. 2014. He was a senior engineer at Samsung Electronics from 2014 to 2015. He was an assistant professor in the Department of Computer Engineering, Keimyung University from 2015 to 2017. He is currently an assistant professor in the Department of Computer Engineering, Changwon National University, Changwon, Korea. His research interests include 5G networks, ultra reliable low latency communication, and Internet of Things. 